Paola Palomino

\title{
El Rey Tunki
}

\section{Wilson Sucaticona y la historia del mejor café del mundo}

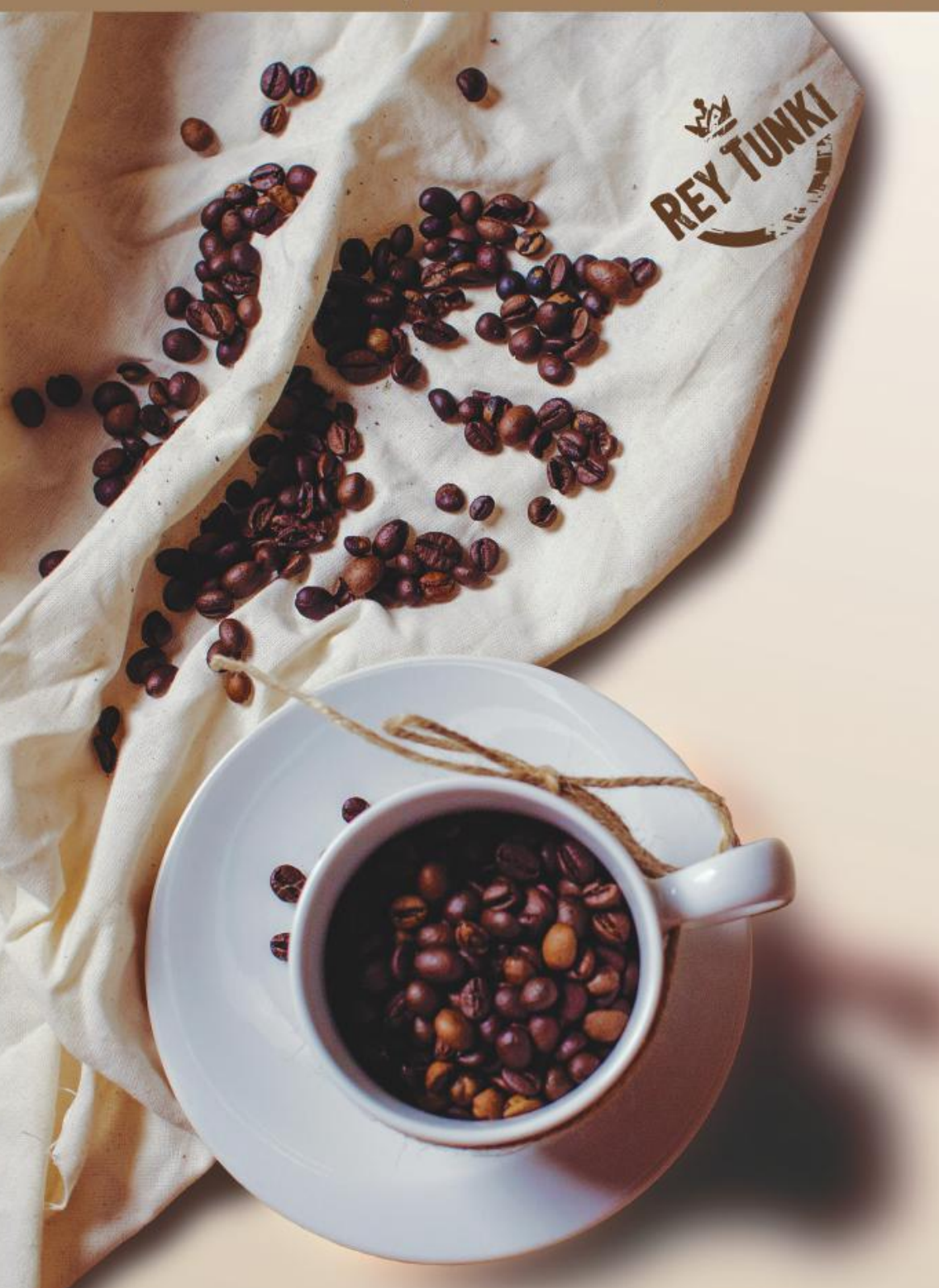




$$
\text { Pa ola Palomino }
$$

\section{El Rey Tunki}

Lima, Agosto de 2016 
(C) Universidad Peruana de Ciencias Aplicadas (UPC)

Primera publicación: agosto de 2016

Impreso en el Perú-Printed in Peru

Autor: Paola Palomino

Edición: Diana Felix

Corrección de estilo: Luigi Battistolo

Diseño de cubierta: Christian Castañeda

Diagramación: Diana Patrón Miñán

Editor del proyecto editorial

Universidad Peruana de Ciencias Aplicadas S. A. C.

Av. Alonso de Molina 1611, Lima 33 (Perú)

Teléf: 313-3333

www.upc.edu.pe

Primera edición: agosto de 2016

Tiraje: 1000 ejemplares

Este libro se terminó de imprimir en el mes de agosto de 2016, en los talleres gráficos de Industria Gráfica Cimagraf S.A. dirección: Psje. Sta. Rosa 220 Ate, Lima - Perú.

\section{BIBLIOTECA NACIONAL DEL PERÚ \\ Centro Bibliográfico Nacional}

633.73

Palomino, Paola.

P21

El rey Tunki : Wilson Sucaticona y la historia del mejor café del mundo / Paola Palomino.-- 1a ed.-- Lima : Universidad Peruana de Ciencias Aplicadas, 2016 (Lima : Cimagraf).

73 p. : il. ; $22 \mathrm{~cm}$.

D.L. 2016-09933

ISBN 978-612-318-057-7

1. Sucaticona, Wilson, 1975- 2. Cafeteros - Perú - Puno 3. Café - Cultivo - Perú - Puno 4. Café - Producción y consumo -Perú - Puno I. Título II. Universidad Peruana de Ciencias Aplicadas

BNP: 2016-173

Hecho el Depósito Legal en la Biblioteca Nacional del Perú nro. 2016-09933

Registro de Proyecto Editorial en la Biblioteca Nacional del Perú nro. 31501401600812

Todos los derechos reservados. Esta publicación no puede ser reproducida, ni en todo ni en parte, ni registrada en o transmitida por un sistema de recuperación de información, en ninguna forma ni por ningún medio, sea mecánico, fotoquímico, electrónico, magnético, electroóptico, por fotocopia o cualquier otro, sin el permiso previo, por escrito, de la editorial.

El contenido de este libro es responsabilidad del autor y no refleja necesariamente la opinión de los editores. 


\section{Contenido}

Prólogo 9

$\begin{array}{ll}\text { Introducción } & 11\end{array}$

Capítulo 1. La esencia de una victoria no lograda 13

$\begin{array}{ll}\text { Capítulo 2. El aroma del éxito } & 17\end{array}$

Capítulo 3. El verdadero sabor $\quad 35$

Capítulo 4. El mejor café del mundo en el sitio más hostil del Perú 39

Capítulo 5. La antesala del olvido $\quad 57$

$\begin{array}{ll}\text { Capítulo 6. A la conquista del mundo } & 61\end{array}$

$\begin{array}{ll}\text { Álbum fotográfico } & 73\end{array}$ 

A todas aquellas personas apasionadas, perseverantes, amantes del café. Y, por supuesto, a ti. 



\section{Prólogo}

\section{Por Karissa Becerra Biaggioni ${ }^{1}$}

Todavía me resulta sorprendente hasta dónde ha llegado el café peruano: gracias a un poco más de cuidado, un poco más de capacitación, mucha voluntad, las manos maravillosas de los agricultores y la ayuda de la tierra, el sol y el agua, en los últimos diez años la calidad del café producido en el Perú mejoró inconmensurablemente.

Esta evolución se puede ver reflejada en la vida de Wilson Sucaticona y su esposa Luz Delia, agricultores comprometidos que hacen su trabajo con pasión y con una determinación invencible.

El rey Tunki muestra la cotidianeidad de estas personas especiales, su lucha por vencer los obstáculos, su hermosa vida en el monte, sus sueños, su fuerza, su fe y cómo todo esto puede ser transformado en algo mágico, como el café que producen. Café que no podría producirse bajo ninguna otra circunstancia.

También muestra el otro lado del éxito, el de las frustraciones, las desilusiones y la tristeza, así como su acercamiento a las reglas demoledoras del mercado. Todo lo que forma parte de la vida de las personas fuertes que nunca dejan de tratar, que saben lo que tienen que hacer de su vida y se dedican a ello de la mejor manera posible.

Es difícil comprender la cantidad de esfuerzo y trabajo emocional y físico alrededor de un cultivo. Solo quien es testigo puede empezar a entender las inmensas dimensiones de esta labor. Creo que, con este libro, Paola Palomino nos ayudará a conocer el valor de este trabajo y el valor de las personas detrás del cultivo, detrás de ese café de la mañana que nos hace tan felices durante todo el día.

1 Autora del libro Café de las nubes, café del Perú. En 2011 obtuvo el segundo lugar en la categoría Mejor Libro del Café en el Gourmand World Cookbook Awards 2011, realizado en Francia. 



\section{Introducción}

El hombre que ha hecho de su café una leyenda vive en una de las zonas más lejanas y hermosas del planeta, entre las nubes de la húmeda y agreste selva en la región de Puno, en el Perú; y, desde lo alto, hace su sueño realidad: cultivar el café orgánico más rico del mundo.

Para llegar a este mágico lugar, donde cada mañana el cielo se viste de azulvioleta, he viajado durante varios meses a Juliaca, también conocida como La Ciudad de los Vientos, ubicada a 3825 metros sobre el nivel del mar. Recorrí 1267,6 km por carretera durante 15 horas de camino accidentado, crucé el Altiplano, subiendo y bajando montañas, laderas, quebradas, ríos y, finalmente, anduve por una imponente montaña empinada cuesta arriba durante tres horas, aproximadamente. Desde lo alto, aves, mariposas, monos y serpientes me daban la bienvenida sobre el estrecho camino que abre paso a un maravilloso colchón de nubes. Da la impresión de estar suspendido en el cielo. Pensé que con el paso de los años se tenderían puentes, carreteras, nuevos caminos, pero no fue así. Llegar a Wilson Sucaticona nunca fue fácil. El periplo de casi cuatro días de movilización desde Lima siempre fue agotador pero gratificante. Sacar fuerzas de donde no había para llegar finalmente a ese lugar que colinda con el cielo y confluye con la selva amazónica hace que uno se llene de una energía especial, no percibida en otra ciudad; ese lugar, que aún conserva suelos vírgenes, aguas cristalinas y un ecosistema casi intacto. Tan intacto que apenas tiene servicios básicos, los caminos están hechos a comba y pala y cada paso a la luz de la luna es incierto.

Durante el tiempo que escribía el libro, Wilson y yo nos sentábamos de madrugada en una banca frente a la chacra a esperar a que aclare el día, 
para iniciar la faena diaria. Recuerdo como si fuera ayer cuando Wilson me miró y me preguntó si sentí el sabor del chocolate. Yo le dije que sí con un movimiento de cabeza. Su taza estaba vacía ya, y sus manos mostraban las cicatrices del trabajo en la tierra, el entrañable cómplice de sus sueños.

Cuando lo conocí, apenas pudimos entablar una conversación. Él se incomodaba con mi castellano y yo hacía esfuerzos denodados por comprender su aymara (lengua materna). Con el paso del tiempo aprendí a conocerlo mejor. Intentó enseñarme su lenguaje y, cuando no se sentía muy conversador, su cuerpo, su rostro y sus manos hablaban por él. Conocer de cerca la historia del hombre que cultiva el mejor café del mundo, cosecharlo junto con él y su familia, vivir de sol a sol su pasión y compartir el arduo trabajo al que se enfrentan cada día terminaron por minimizar los peligros a los que me he tenido que enfrentar cada vez que realizaba esas largas travesías.

Hoy, a pesar de haber emprendido una nueva etapa y cruzado fronteras, sigue siendo la misma persona sencilla que conocí, continúa disfrutando del rancho frío y los amaneceres en la chacra. Sus 41 años están llenos de vitalidad y sobre todo de esa energía contagiosa que se desborda cada vez que conversamos de su pasión.

Convivir con los Sucaticona, cosechar con ellos, compartir su paraíso terrenal y disfrutar del café recién molido en su chacra, en casa de su familia en Juliaca o en Lima, y catarlo con expertos baristas en California, Estados Unidos, representó para mí un quiebre mental entre la realidad y lo que uno desea perseguir. Después de haberlos acompañado durante años, seguido de cerca y de lejos, hoy valoro más la fortaleza con la que deciden enfrentar la vida día a día, con el único motivo de perseguir y hacer realidad su sueño.

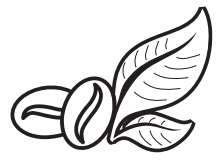

Gracias por acompañarme en este viaje. 


\section{Capítulo 1. La esencia de una victoria no lograda}

«iEl ganador por el mejor café especial y campeón mundial de 2010 es el Tunki de Wilson Sucaticona, del Perú!», se escuchó por los parlantes del Hall B en el Centro de Convenciones de Anaheim en California, donde se realizaba la XXII Feria de la Asociación de Cafés Especiales de América, la convención anual de café más importante del mundo.

La ovación del público era interminable. Muchos estaban gratamente sorprendidos de que ganara por primera vez un peruano en la categoría de mejor café especial de origen. Era un domingo de abril del año 2010 alrededor de la una de la tarde, y la delegación peruana apenas podía creer el resultado. La espera había sido agobiante. Todavía sin asumirlo, el ingeniero Javier Cahuapaza Mamani, en ese entonces secretario comercial adjunto de la cooperativa que presentó el café Tunki al concurso, subió al escenario del auditorio principal para recibir el premio. «No lo podíamos creer, habíamos vencido a fuertes competidores de Brasil, Vietnam y Colombia - recuerda ahora, sentado en su oficina en Lima-. De pronto éramos campeones».

Unas 10000 personas de 75 países diferentes —entre ellos traders, brokers, tostadores, importadores, retailers, baristas y público relacionado con el mundo cafetalero- se habían reunido en esta feria. 
La Asociación de Cafés Especiales de América (SCAA por sus siglas en inglés) es la organización de café sin fines de lucro más grande del planeta. Supera los 10000 miembros en todo el mundo y, desde 1982, organiza anualmente una exposición en la que se premia a los mejores cafés en el ámbito internacional. La feria fue creada en 1988 por un grupo de profesionales en café. Desde entonces, la Specialty Coffee Association of America ha celebrado 28 ediciones en Estados Unidos y ha promovido la calidad, estableciendo altos estándares internacionales.

Ese domingo de abril de 2010, la sala estaba atiborrada de gente y los integrantes de la Central de Cooperativas Agrarias Cafetaleras de los Valles de Sandia (Cecovasa) que lograron viajar celebraban el triunfo del café peruano Tunki. Esta delegación estuvo compuesta por Javier Cahuapaza Mamani; Miguel Paz, gerente de Ventas; Daniel Apaza Canaza, presidente del Consejo de Vigilancia; Hernán Tito, trabajador del Consejo; y César Rivas, presidente de la Junta Nacional del Café (JNC).

La emoción tenía una razón, más allá de la normal satisfacción que produce un triunfo. El premio entregado por la SCAA era un diploma de certificación que acreditaba que en ese fundo peruano llamado Tunki se producía el mejor café orgánico del mundo. El Perú había participado en la Feria de Cafés Especiales desde el año 1997². En 2002 tuvo la oportunidad de participar con la Comisión de Promoción del Perú para la Exportación y el Turismo (PromPerú) y, desde 2007, con la JNC . Desde entonces hasta 2010, esta junta llevó a la feria un promedio de 20 organizaciones, pero ni el más optimista de los cálculos pudo prever la consecución de un título mundial.

La elección había sido ardua, en dos tandas de votación a cargo de 30 catadores, quienes degustaron 139 muestras de café de 25 países

2 De acuerdo con la entrevista realizada a Miguel Ángel Paz López, gerente comercial de la Central de Cooperativas Agrarias Cafetaleras de los Valles de Sandia (Cecovasa).

3 De acuerdo con la entrevista realizada a Lorenzo Castillo, gerente de la Junta Nacional de Café. 
durante dos días. Primero se había escogido a los nominados de una lista ya propuesta, de la que resultaron cinco finalistas. En la segunda tanda de votaciones se seleccionó al ganador.

La noticia llegó al Perú a las seis y veinte de la tarde de ese mismo día, a través de la agencia de noticias Inforegión. El telegrama, bastante serio, decía: «Café fino de Puno clasificó para el premio El Café del Año 2010 en Estados Unidos». Dos días después, el martes 20 de abril de 2010, a las dos y cinco de la tarde, el diario más influyente del Perú, El Comercio, lanzó una nota virtual con un título más vendedor: «El café peruano fue premiado en Estados Unidos». El mismo día, el diario Los Andes, de Puno, emitió su nota: «Café de Puno se ubica entre los mejores del mundo». A partir de ese momento, el rebote en los medios se volvió viral. «El café puneño es el mejor del mundo», anunciaba el periódico Perú 21.

David Anco Cahuapaza, catador y responsable de control de calidad de Cecovasa de Puno, explica, desde la sede de la cooperativa, los puntos que se evaluaron para calificar de una manera tan alta al Tunki de Sucaticona. En el laboratorio de Cecovasa los catadores prueban cuidadosamente los cafés y determinan las observaciones necesarias para la mejora de estos. Las características que tienen en cuenta son fragancia, aroma, sabor, sabor residual, cuerpo, acidez, balance, uniformidad, taza limpia y puntaje del catador. Entre estos criterios resalta el de taza limpia, que significa que el café está elaborado con granos de la mejor calidad, excluyendo los verdes, maduros y dañados. El café de Sucaticona había sido catado por Anco antes de ser enviado a los concursos, y había recibido de su parte 90 puntos, de acuerdo con sus atributos. «El Tunki tiene una fragancia floral, con una acidez final bastante brillante que llega elegantemente a nueve puntos y que además se deja acompañar por un sabor intenso a chocolate. Son pocos los cafés así». Anco termina de decir esto y cierra los ojos mientras respira el olor de la taza de café caliente que lleva en las manos. 
Durante los siguientes días, la comitiva peruana se fue enterando de que su café se había impuesto a 139 muestras de 25 países en su categoría, entre los que figuraban naciones cafetaleras por excelencia, como Colombia, Kenia y Panamá. El puntaje que obtuvo fue de 89,2 y la deliberación se hizo sobre la base de cuatro criterios principales: apreciaciones visuales, características olfativas, características gustativas y aspectos táctiles. El Tunki resaltó principalmente por la acidez, el cuerpo y el delicado aroma floral. Tunki Coffee, como se denominó desde entonces de modo comercial al café que produce Sucaticona, se impuso sobre todas las muestras. Asimismo, fue ganador en el People Choice Award, una suerte de «premio del público». En este caso, gracias a la votación popular, el Tunki de Sucaticona fue nuevamente aclamado, aun cuando Colombia era el país favorito. Con el paso de los días, los elogios se multiplicaron. Sin embargo, a 7503 kilómetros de distancia, el dueño de tan exquisito y vanagloriado producto, Wilson Sucaticona Larico, no sospechaba que en el otro hemisferio del planeta su café había sido el ganador entre los mejores del mundo. 
Para poder revisar todo el contenido de esta edición, visite nuestra tienda virtual.
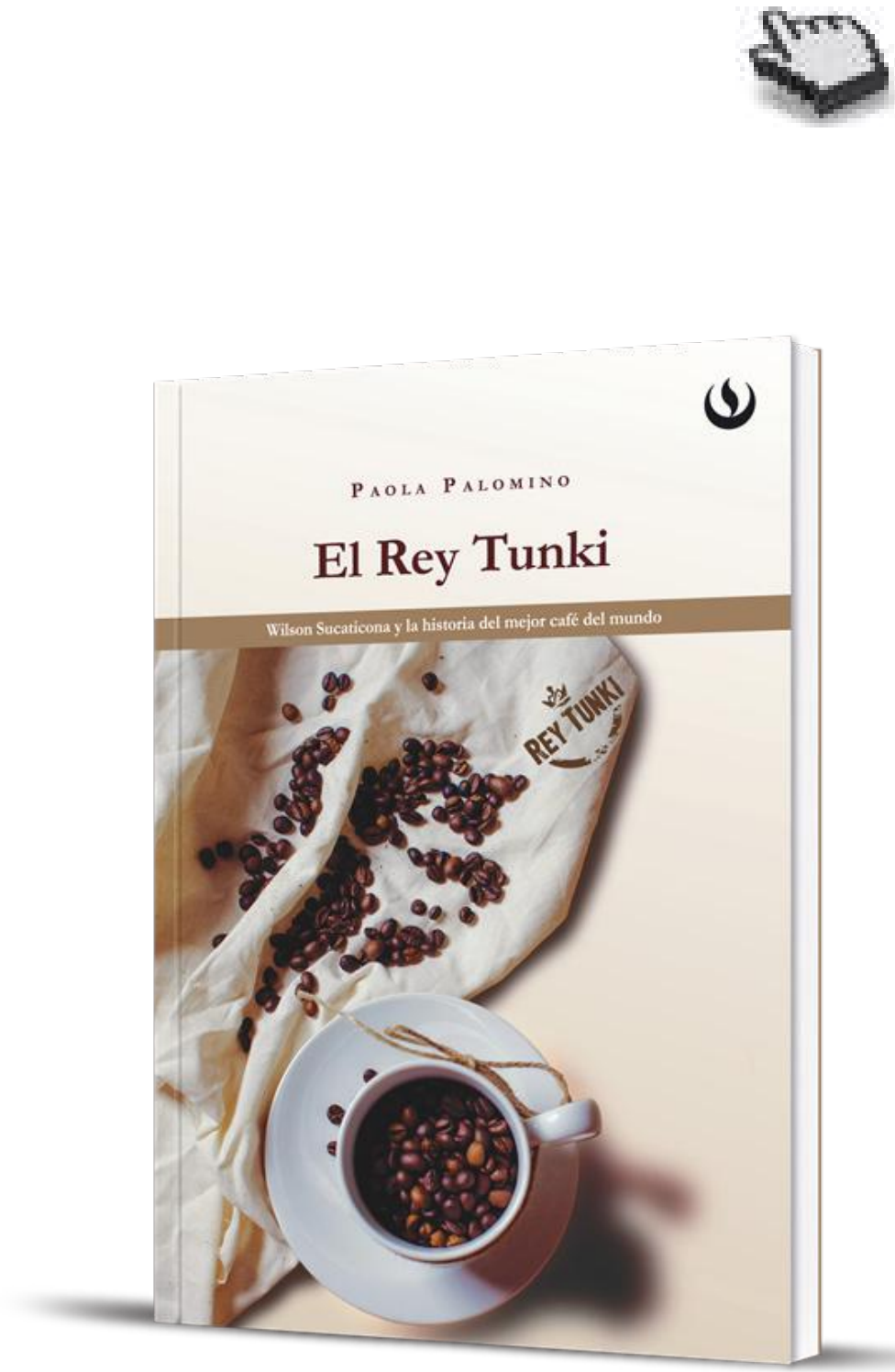